\title{
Hiperpresidencialismo y derechos fundamentales en tiempos de COVID-19. Un análisis del caso
}

\section{paraguayo}

Hyperpresidentialism and fundamental rights in times of COVID-19. An analysis of the Paraguayan case

Autores: Camilo Filártiga Callizo, Rodrigo Ayala Miret

DOl: https://doi.org/10.19053/16923936.v18.n36.2020.12162

Para citar este artículo:

Filártiga Callizo, C. y Ayala Miret, R. (2020). Hiperpresidencialismo y derechos fundamentales en tiempos de COVID-19. Un análisis del caso paraguayo. Derecho y Realidad, 18, (36), 161- 180. 


\title{
HIPERPRESIDENCIALISMO Y DERECHOS FUNDAMENTALES EN TIEMPOS DE COVID-19. UN ANÁLISIS DEL CASO PARAGUAYO*
}

\author{
Hyperpresidentialism and fundamental rights in times of COVID-19. An analysis of the \\ Paraguayan case
}

Hiperpresidencialismo e direitos fundamentais na época da COVID-19. Uma análise do caso paraguaio

\section{Camilo Filártiga Callizo ${ }^{\mathbf{a}}$}

cfilartigacallizo@gmail.com

\author{
Rodrigo Ayala Miret ${ }^{b}$ \\ rodrigoayalamiret@gmail.com
}

Recepción: 08 de noviembre 2020

Aceptación: 27 de noviembre 2020

\section{RESUMEN}

A lo largo del tiempo, la división clásica de poderes del Estado se ha mantenido fundamentalmente, sin embargo, cambios no menores como el desarrollo progresivo de los derechos, la responsabilidad estatal para la garantía de los mismos - reflejados en el Estado Social de Derecho-, entre otras condiciones y cambios jurídicos, sociales y políticos, han transformado trascendentalmente el funcionamiento, la acumulación de poder y el equilibrio proyectado de los poderes públicos.

Dentro de este contexto, la pandemia de COVID-19 no transformó esta realidad, sino que la ha agudizado, exponiendo de manera más visible la progresiva acumulación de poder en el Ejecutivo. El presente ensayo tiene por propósito exponer lo señalado anteriormente $\mathrm{y}$, al mismo tiempo, hacer un llamado de atención para cuidar la vigencia continua de un verdadero equilibrio formal y material- de los poderes del Estado, de manera que los mismos funcionen correcta y coordinadamente para la misión que fueron creados: proteger y garantizar la libertad, la democracia constitucional y los derechos fundamentales.

\section{PALABRAS CLAVES}

Paraguay; Derechos Humanos; Derecho Constitucional; Poder Político; Pandemia; Hiperpresidencialismo; COVID-19.

* Artículo de reflexión.

a. Abogado, Universidad Católica "Nuestra Señora de la Asunción”. Máster en Estudios Políticos Aplicados. Especialista en Transparencia y Anticorrupción por el Centro de Derechos Humanos de la Universidad de Chile. Investigador del CONACYTPARAGUAY y docente universitario. @CamiloFilartiga

b. Abogado, Universidad Católica "Nuestra Señora de la Asunción". Máster en Justicia Constitucional y Derechos Humanos, Universidad de Bologna (Italia). Profesor de Derecho (UC, Asunción). 


\section{ABSTRACT}

Over time, the typical separation of powers has essentially been maintained. However, non-minor changes such as the progressive development of rights, the responsibility of the State to guarantee them - reflected in the welfare state-, among other legal, social and political changes and conditions, have transcendently transformed the functioning, the accumulation of power and the designed balance of public power.

Within this context, the Covid-19 pandemic did not transform this reality, but rather, intensified it exposing more clearly the progressive accumulation of power of the Executive Branch. The purpose of this paper is to expose the above mentioned and simultaneously to raise awareness in order to ensure a continuous and real balance of State powers. For these to function correctly and coordinately according to the mission they were designed for: to protect and guarantee freedom, constitutional democracy, and fundamental rights

\section{KEYWORDS}

Paraguay; Human Rights; Constitutional Law; Political Power; Pandemic; Hyper presidentialism; COVID-19.

\section{RESUMO}

Ao longo do tempo, a clássica divisão dos poderes do Estado tem se mantido fundamentalmente, porém, sem pequenas alterações como o desenvolvimento progressivo dos direitos, a responsabilidade do Estado por garanti-los - refletida no Estado Social de Direito - , entre outras condições e mudanças jurídicas, sociais e políticas, transformaram transcendentalmente 0 funcionamento, a acumulação de poder e o equilíbrio projetado dos poderes públicos.

Nesse contexto, a pandemia COVID-19 não transformou essa realidade, mas a exacerbou, expondo de forma mais visível o acúmulo progressivo de poder no Executivo. 0 objetivo deste ensaio é apresentar o exposto e, ao mesmo tempo, fazer uma chamada à atenção para zelar pela validade contínua de um verdadeiro equilíbrio formal e material - dos poderes do Estado, para que funcionem corretamente e em coordenação. pela missão que foram criadas: proteger e garantir a liberdade, a democracia constitucional e os direitos fundamentais.

\section{PALAVRAS-CHAVE:}

Paraguai; Direitos Humanos; Direito Constitucional; Poder Político; Pandemia; Hiperpresidencialismo; COVID-19.

\section{INTRODUCCIÓN}

La tradición de gobiernos autoritarios en el Paraguay es una característica transversal a toda la historia política del país, tanto así, que estos 31 años desde la caída de la dictadura de Alfredo Stroessner son los de mayor tiempo vividos en un régimen de libertades y de democracia ininterrumpidas.

El artículo presenta un recorrido sucinto del desarrollo político y constitucional en el Paraguay hasta nuestros días, describiendo aspectos fundamentales del diseño constitucional de 1992 y cómo ese diseño quiebra formalmente los modelos de Estado previstos en las constituciones anteriores, consagrando a su vez, un catálogo ambicioso de libertades, derechos, garantías e instituciones democráticas.

A lo largo del tiempo, la división clásica de poderes del Estado (Ejecutivo-LegislativoJudicial) en su mayoría se ha mantenido formalmente pero su funcionamiento material ha variado de manera trascendental, tanto, que lo ha modificado (Ayala Miret, 2020).

La ampliación y el desarrollo progresivo de los derechos y la mayor protección estatal para la garantía de los mismos reflejada por el Estado Social de Derecho, tuvo por consecuencia un crecimiento sustancial respecto a la estructura estatal, a las funciones y a la cantidad de funcionarios, siendo en esta transformación el Poder Ejecutivo el de mayor crecimiento en cuanto a su estructura, funciones y poder (Ayala Miret, 2020). 
El diseño institucional formal previsto en la carta magna, sin embargo, establece amplias facultades de control para el Poder Legislativo y, en menor medida, el Judicial, sobre el Poder Ejecutivo, condición que fue calificada por juristas y estudiosos del derecho como un "sistema formal de presidencialismo atenuado".

Dentro de este contexto, de esta nueva realidad (o desequilibrio) en el funcionamiento de los poderes del Estado, la pandemia del COVID-19 no transformó esta realidad sino que la ha agudizado.

El Covid-19 ha sido la excusa perfecta para un uso extensivo de facultades por parte del Ejecutivo, limitando libertades fundamentales $y$ facultando a la fuerza pública a imputar y privar de su libertad a aquellos ciudadanos que "violen la cuarentena", en base a decretos $\mathrm{y}$ resoluciones basados en normativas anteriores a la Constitución de 1992 y, por supuesto, de inferior jerarquía normativa.

A lo largo del presente artículo, se tendrá por objetivo hacer un recorrido a los antecedentes pre-democráticos del Paraguay, explorando sus condiciones sociales, institucionales y culturales respecto al ejercicio del poder público. De la misma manera, analizar la identidad de la Constitución de 1992, sus objetivos, su carácter anti-autoritario y las tendencias comparadas ante las cuales se encuentra en la actualidad.

De esta forma y conociendo estos antecedentes, se hará una descripción analítica de los hechos y de las normas legales y administrativas - expedidas en ocasión a la pandemia global de Covid-19. Finalmente, se analizará críticamente conforme a la Constitución paraguaya de 1992 el funcionamiento de los poderes del Estado y el estado de los derechos protegidos por ella durante la pandemia.

\section{LA TRADICIÓN AUTORITARIA DEL PODER EJECUTIVO EN EL PARAGUAY}

El Paraguay tiene una larga historia de gobiernos militares - autoritarios, cruzada además por dos guerras internacionales, la primera de ellas conocida mundialmente como la "Guerra de la Triple Alianza", en la que el país se enfrentó a Argentina, Brasil y Uruguay, entre los años 1864 a 1870, y donde el Paraguay perdió entre el $60 \%$ y $70 \%$ de la población total del país (Areces, 2010). Lo anterior, dejó al territorio deshecho en lo que respecta a su tejido económico, social, político y cultural. Tan sólo 62 años después, el país se enfrentaría a una segunda conflagración esta vez contra el país hermano de Bolivia, guerra que tuvo lugar entre los años 1932 a 1936. Durante ese período de tiempo, el país se rigió por la Constitución de 1870, cuerpo normativo de tipo liberal, concebido durante la ocupación de las tropas aliadas en el país, y tutelada por las fuerzas aliadas victoriosas en aquella contienda (Filártiga Callizo, 2016).

En 1936, la Revolución Febrerista, conducida por el coronel Rafael Franco, héroe militar de la guerra del Chaco con Bolivia, derrocó al gobierno liberal de turno, marcó la fundación del Partido Revolucionario Febrerista, y inició un largo período de regímenes de corte militar-autoritario. Por su parte, Franco dictó el decreto $\mathrm{N}^{\circ} 152$ en el año 1936, por el cual derogó irregularmente la constitución vigente de 1870 y proscribió los partidos políticos. A partir de ese momento, las Fuerzas Armadas emergieron como los principales actores de la estructura política del Estado.

Entre 1936 y 1954, con el agregado de las Fuerzas Armadas como factor determinante en el equilibrio del poder, la convivencia política estuvo dominada por la intolerancia y el sectarismo. En este momento, la inestabilidad política fue una constante, tanto así, que entre 1870 y 1954 llegaron al poder 43 presidentes (Filártiga Callizo, 2016). A partir del año 1954 se inicia el periodo de gobierno autoritario de Alfredo Stroessner, que se extendió hasta 1989 , año en el que se produce el golpe de Estado que lo expulsa del poder. Dicho periodo se caracterizó por la represión sistemática de los derechos humanos, la institucionalización de prácticas 
de corrupción en la administración pública, y la suspensión sistemática de algunas libertades y ciertos derechos fundamentales. Este oscuro régimen se sustentó con ayuda de las Fuerzas Armadas ${ }^{1}$ y el Partido Colorado, por medio de una estructura de gobierno al servicio de los intereses del dictador, en donde Stroessner era el jefe de los tres sectores de poder.

A diferencia de otros regímenes dictatoriales en América Latina, el paraguayo no creó una nueva estructura política o partido para gobernar, sino que se valió del Partido Colorado para dicho fin (Filártiga Callizo, 2016). A lo largo de más de tres décadas, realizó una lenta pero continua tarea de adecuación y eliminación de sus opositores, así como de represión sistemática de los derechos humanos y libertades fundamentales. Durante su gobierno, el funcionamiento de los partidos políticos opositores y de los demás poderes del Estado, eran sólo una fachada. La concentración del poder en su persona era total, con el sometimiento obsecuente de los otros poderes del Estado. Si bien se realizaban formalmente elecciones, no existían condiciones políticas para una alternancia, puesto que los procesos electorales no reunían los requisitos mínimos para garantizar dicho fin.

La Constitución de 1940 rigió durante los primeros 13 años de mandato del tirano Stroessner, quien gobernó amplios periodos de su extenso mandato recurriendo a la figura del Estado de sitio, prevista en las constituciones de 1940 y de 1967. La constitución de 1940, de corte autoritaria, fue promulgada por decreto del presidente José Félix Estigarribia. Dicha carta magna permitía la reelección por un período de cinco años y otorgaba amplias facultades al Poder Ejecutivo, ya que le permitía: declarar el Estado de Sitio ante alguna amenaza interna o conflicto exterior; nombrar a miembros de la Corte Suprema de Justicia, del Tribunal de Cuentas, y a los funcionarios de la Administración de Justicia; disolver el Poder Legislativo convocando a nuevas

1. De las que Stroessner era Comandante en Jefe. elecciones; dictar decretos con fuerza de ley durante el receso parlamentario, entre otras.

En el año 1967, se promulga una nueva constitución que manifestó formalmente una democracia de tipo representativa, la separación de poderes, equilibrio e interdependencia. Era una constitución confesional, puesto que adoptó como religión oficial el catolicismo apostólico romano, siendo además un requisito establecido en el art. 172 el profesar dicha religión para ser presidente de la república. Esta carta magna, sobre la cual operaba en la práctica un régimen autoritario, que violentaba derechos humanos de forma sistemática, reservaba al presidente facultades como la de declarar el estado de sitio (art. 181) o decretar la disolución del Congreso "por hechos graves que le sean imputables" (art. 182). Asimismo, nombraba además a los miembros de la Corte Suprema, al Fiscal General del Estado (con acuerdo del Senado), y a los miembros de tribunales inferiores, jueces y demás magistrados del Poder Judicial (con acuerdo de la Corte Suprema de Justicia). Además, dejaba a determinación de la ley el modo de elección de las autoridades subnacionales como intendentes municipales y delegados de gobierno departamentales, quienes de esta manera eran designados por el presidente. De este modo, la centralización política en el presidente de la república era total: "La dominación del régimen stronista estaba basada en un sistema calculado de recompensas y castigos, que no dejaba nada a la improvisación o la suerte. El orden legal que apuntalaba el régimen podría ser ajustado tanto como sea necesario, en orden a ajustarlo a los deseos discrecionales del jefe de Estado." (Marcial Riquelme, 1994, p. 43). Al respecto, vale la pena señalar que el mismo Riquelme definió al régimen de Stroessner como "sultanista", forma de gobierno personalizada y centralizada, en la que los funcionarios se reclutan sobre la base de la lealtad personal al gobernante.

\section{UN NUEVO ESTADO PARA LA NUEVA DEMOCRACIA}

Los paraguayos tuvimos que esperar hasta finales de la década del 80 para presenciar la caída de la dictadura del Gral. 
Alfredo Stroessner, mientras la mayoría de los países de la región ya estaban en democracia. En febrero de 1989 se produce un golpe militar que tuvo como objetivos internos un conjunto de reformas limitadas para superar las contradicciones políticas y modificar el papel del Estado en la vida económica (Fretes Carreras, 2003). Aunque algunos autores como Andrew Nickson (2010) sostienen que la intención principal del golpe militar, antes que democratizar el país, fue restablecer la relación armónica entre las Fuerzas Armadas y el Partido Colorado, que había sido seriamente dañada en los años previos.

En el año 1991 se convocó a una Asamblea Nacional Constituyente que reformaría la Constitución de 1967 para ajustarla a los tiempos más democráticos. La Constitución promulgada en el año 1992 constituye un quiebre del modelo heredado de la dictadura stronista. La nueva Constitución posicionó claramente al Estado como un agente protagónico de cambio en el Paraguay, con un activo rol en la promoción y la garantía de los derechos. El mensaje era claro, el Estado autoritario que con el stronismo era instrumento de supresión de derechos y libertades, en democracia debía ser el principal garante de los derechos fundamentales. La nueva Constitución reivindica —desde el preámbulo- la dignidad humana, con el fin de asegurar la libertad, la igualdad y la justicia en el marco de una democracia representativa, participativa y pluralista, constituyendo para ello un Estado social de derecho. Dicha innovación planteó una transformación en la concepción del Estado y de su rol como garante efectivo de los derechos fundamentales.

Teniendo en cuenta el largo y reciente pasado autoritario, la idea de control y equilibrio del poder se evidencia a lo largo del texto constitucional que organiza el poder público dispersándolo en los tres poderes clásicos - Legislativo, Ejecutivo y Judicial- en un sistema de independencia, equilibrio, coordinación y recíproco control. De la misma forma, no permite que ninguna de las ramas se atribuya ni otorgue a terceras facultades extraordinarias o la suma del Poder Público. Sumado a ello, la Constitución de 1992 introdujo la descentralización política, territorial y administrativa; asegurando la elección por voto popular en los niveles de gobiernos subnacionales y locales. Además, en un intento por reordenar los sistemas de balances y contrapesos entre poderes concede al Poder Legislativo prerrogativas más amplias para controlar la gestión de los demás poderes. (Mateo Balmelli, 1995).

Esto representó un cambio significativo, teniendo en cuenta que durante los años de dictadura stronista, el tirano elegía personalmente quienes serían los "delegados departamentales", que no eran más que informantes del Régimen en cada región del país. Este modelo nefasto se rompe con la elección democrática popular de los gobernadores departamentales por parte de sus propios electores locales.

Además, la Constitución de 1992 dispone la creación de órganos autónomos "extrapoderes" que ejercen la "accountability horizontal", ${ }^{2}$ como la Contraloría General de la República, el Ministerio Público, la Justicia Electoral, el Consejo de la Magistratura y el Jurado de Enjuiciamiento de Magistrados ${ }^{3}$. Todos ellos tendientes, en mayor o menor medida, a poner más filtros y controles al poder político.

En concordancia con el modelo de democracia participativa se garantiza en la Constitución el ejercicio de la libertad de expresión y el derecho de acceso a la información pública, el derecho a peticionar a las autoridades, la defensa de intereses difusos, así como los instrumentos de democracia directa como el referéndum y la iniciativa popular. Los cuales, previstos en los artículos 121 y 123, respectivamente, son escasamente implementados en democracia.

2. Capacidad de órganos estatales de supervisar la gestión de otras instituciones del Estado, y de sancionar a éstas, en caso que hubieren actuado fuera de la legalidad. 3. Estos dos últimos para la selección y remoción de los jueces, respectivamente. 
Si se toman en cuenta las disposiciones previas de las Constituciones de 1940 y de 1967, de corte autoritario y caudillista, que reservaban amplias atribuciones para el presidente de la República, en contraposición, notamos que la Constitución de 1992 apunta en primer lugar al equilibrio y al recíproco control entre los poderes del Estado, encaminándolos a coordinar sus acciones de modo que ninguno se superponga al otro.

Este rediseño institucional garantizó hasta el momento la vigencia de la democracia paraguaya, al actuar de freno a los intentos de regresión autoritaria y de extensión de mandatos de algunos presidentes más allá del plazo constitucionalmente dispuesto. En este sentido los últimos 3 expresidentes electos, Duarte Frutos (20032008), Fernando Lugo (2008-2012) y Horacio Cartes (2013-2018), han intentado inconstitucionalmente imponer la reelección vía enmienda, generando profundas crisis políticas que derivaron en movilizaciones sociales que frustraron estos intentos. Incluso, en el año 2017, se produjo un acto que podría encuadrarse como propio del terrorismo de Estado, cuando agentes de la policía nacional irrumpieron en el local del Partido Liberal Radical Auténtico, principal partido opositor al gobierno, y asesinaron de manera premeditada por la espalda a un joven dirigente de nombre Rodrigo Quintana, en el marco de las movilizaciones ciudadanas de rechazo a la intención del expresidente Cartes de imponer la reelección vía enmienda inconstitucional.

Sobre la reelección es oportuno mencionar que la Constitución en su artículo 229 (De la duración del mandato), establece el plazo de cinco años improrrogables de duración del mandato para presidente y vicepresidente, y la prohibición expresa de la reelección presidencial al decir: no podrán ser reelectos en ningún caso. El diseño institucional mencionado, de frenos y contrapesos, ha exigido además a los presidentes de la república, capacidad de diálogo y negociación con el Poder Legislativo a fin de viabilizar proyectos de leyes y políticas públicas. Lo anterior, está condicionado a mayorías políticas que necesita el Ejecutivo en el Congreso para gobernar democráticamente. En muchos casos, aun teniendo mayoría circunstancial, eso no garantiza la gobernabilidad, debido al faccionalismo que padece el sistema de partidos paraguayo.

En cuanto a los mecanismos de control formal previstos en la Constitución, el Legislativo es quien posee facultades más amplias de regulación sobre los demás poderes, pudiendo mencionarse entre otros: la solicitud de informes a los poderes del Estado, a los entes autónomos, autárquicos y descentralizados, y a los funcionarios públicos. De la misma forma, la interpelación a ministros, aunque sin carácter vinculante; la formación de comisiones de investigación; el juicio político al presidente, al vicepresidente, a ministros y a otros altos cargos públicos (artículos 192 a 195 y 225, respectivamente). Respecto al Poder Judicial, en especial son relevantes las facultades concedidas a la Corte Suprema de Justicia para el control de constitucionalidad de las normas jurídicas y resoluciones judiciales, previstas en los artículos 132, 259 inc. 5 y 260. Sin embargo, la declaración de inconstitucionalidad sólo produce efectos inter-partes y para cada caso concreto.

Finalmente, cabe destacar que el Poder Ejecutivo goza de la facultad del veto total o parcial de las leyes sancionadas por el Congreso, formulando las observaciones que estime convenientes, prevista en el art. 238 inc. 4). Dicho veto sólo puede ser superado por una mayoría absoluta (mayoría del número total de miembros) de ambas Cámaras del Congreso para confirmar su sanción, para luego ser enviado al Ejecutivo para su promulgación y publicación, conforme a los artículos 185, 208 y 209 de la Constitución.

\section{LOS DISEÑOS INSTITUCIONALES EN PERSPECTIVA COMPARADA}

Un elemento no menor que tuvo su incidencia en la consolidación de poderes delegativos en la región son las políticas de cambio constitucional operadas en América Latina, bajo las cuales los Poderes 
Tabla 1. Reformas constitucionales que incorporan la figura de la reelección inmediata. Países y años.

\begin{tabular}{|c|c|c|}
\hline PAÍSES & AÑO DE REFORMA & TIPO DE REELECCIÓN \\
\hline Perú & 1993 & Inmediata, por un periodo más. \\
\hline Argentina & 1994 & Inmediata, por un periodo más. \\
\hline Brasil & 1997 & Inmediata, por un periodo más. \\
\hline Venezuela & 1999 & Inmediata, por un periodo más. \\
\hline Colombia & 2005 & Inmediata, por un periodo más. \\
\hline Bolivia & 2009 & Inmediata, por un periodo más. \\
\hline
\end{tabular}

Fuente: Elaboración propia.

Ejecutivos, en su mayoría, fueron reforzados, incorporándose las reelecciones (alternas, inmediatas y hasta indefinidas) y otras facultades políticas, como la promulgación de decretos de necesidad y urgencia y el aumento de los poderes legislativos del presidente, frente al debilitamiento de los poderes Legislativo y Judicial.

Gabriel Negretto, en su libro "La política del cambio constitucional en América Latina" (2015), destaca la incorporación de reglas de reelección más permisivas en la región en los últimos años, constatándose un aumento sostenible a partir del año 1994 hasta el año 2008. En este sentido, justamente los países que se toman como modelos de gobiernos delegativos establecen reformas constitucionales a fin de incorporar la reelección inmediata en sus constituciones: Brasil (1997), Perú (1993) y Argentina (1994); a estos se suman una ola "reeleccionista" en los casos de Venezuela (1999), República Dominicana (2002),

Tabla 2. Reformas constitucionales que incorporan la figura de la reelección indefinida.

\section{Países y años.}

\begin{tabular}{|c|c|c|}
\hline PAÍSES & AÑO DE REFORMA & TIPO DE REELECCIÓN \\
\hline Venezuela & 2009 & Indefinida \\
\hline Nicaragua & 2014 & Indefinida \\
\hline Ecuador & 2015 & Indefinida \\
\hline
\end{tabular}

Fuente: Elaboración propia. 
Colombia (2005) y Bolivia (2009) que incorporan la reelección inmediata por una vez. A continuación, el lector verá una tabla con los datos anteriormente señalados:

Posteriormente, esta tendencia avanza hacia establecer la figura de la reelección indefinida, como son los casos de Venezuela, Ecuador y Nicaragua. En el caso de Ecuador, se incorpora la reelección en la Constitución de 2008, y se restan varias facultades al Poder Legislativo, para luego en 2015 incorporar la reelección indefinida. Dichos aspectos, reforzaron indudablemente el presidencialismo, al concentrar el poder en la figura del presidente Correa. En el caso de Bolivia, un fallo del Tribunal Constitucional del año 2017 autorizó la reelección indefinida del presidente Evo Morales, contradiciendo lo establecido en la norma constitucional de la reelección inmediata sólo por un periodo, desconociendo además los resultados del referendo realizado en 2016, en el que los ciudadanos rechazaron hacer una reforma a la carta magna para eliminar el límite de reelecciones. Este fallo autoriza a Morales a presentarse nuevamente en las elecciones generales del 2019.

Actualmente, tanto Colombia (2015) vía Congreso Nacional como Ecuador (2018) vía consulta popular han retrocedido en las ampliaciones normativas respecto a la reelección, eliminando la misma para el caso colombiano y limitando a dos periodos para el caso ecuatoriano. Es importante destacar la frecuencia con que los presidentes en funciones en distintos países ejercen presión para sancionar reformas que permitan la reelección consecutiva del Ejecutivo cuando ello no está permitido en la constitución existente. Dicha presión sugiere que la tendencia hacia reglas de reelección más permisivas continuará en el futuro próximo (Negretto, 2015).

Contraria a la tendencia de los cambios constitucionales, operados en varios países de América Latina, en el caso paraguayo, la Constitución en 1992 limitó el mandato del Poder Ejecutivo a un solo período de cinco años sin posibilidad de reelección y dotó de amplias facultades al Poder Legislativo, en un régimen que permanece formalmente como un "presidencialismo moderado". Como bien se sabe, Paraguay es de los pocos países en la región, junto con México, Colombia (desde el 2015) y Guatemala, que prohíben de manera absoluta la reelección presidencial, y tampoco prevén facultades extraordinarias como la promulgación de decretos de necesidad y urgencia y el aumento de los poderes legislativos del presidente.

A esto se debe agregar que la Constitución paraguaya de 1992 no ha sufrido enmiendas sustanciales en los casi 30 años de su vigencia, apenas una sola enmienda constitucional en materia electoral que permitió a los paraguayos residentes en el extranjero votar en las elecciones generales, que aunque saludable para la democracia no ha tenido una incidencia sustancial en la vida política y social del país. Esta situación no se compadece con lo ocurrido en la mayoría de los países en América Latina, que solo en los últimos 30 años han tenido diversas enmiendas y reformas constitucionales.

El diseño constitucional de 1992 decantó formalmente en un sistema "híbrido", declarándose el sistema político paraguayo como presidencialista. Sin embargo, la redistribución de funciones y competencias de los poderes propuesta en la Constitución amplió considerablemente las facultades para el Legislativo respecto a las anteriores constituciones. Este diseño institucional ha llevado a importantes autores a sostener que bajo la Constitución de 1992, el Poder Ejecutivo tiene un poder normativo llamativamente débil y un liderazgo político institucional muy limitado (Mendonca: 2004). No obstante, los últimos 28 años bajo esta Constitución demuestran lo contrario. Para conocer la dimensión y el equilibrio real de los poderes del Estado no basta con una mirada a las atribuciones formales establecidas en la Constitución, sino que además, debe levantarse la mirada por sobre la Constitución formal y observar esas atribuciones en funcionamiento, por medio de un análisis profundo de sus dimensiones en cuanto al funcionamiento real y complejo del poder (Ayala Miret, 2018). 
Analizar y juzgar esas atribuciones por su peso real en el mundo jurídico, político y social. En este sentido, la pandemia de COVID-19 ha sido una verdadera oportunidad para observar el funcionamiento y la correlación real de fuerzas de los poderes del Estado en su más fiel expresión, funcionamiento que no se ha transformado sino que se ha intensificado.

\section{EL SISTEMA Y EQUILIBRIO DE PODERES DURANTE LA PANDEMIA DE COVID-19}

Como bien manifiesta el Dr. Jorge Alejandro Amaya, en nombre de la "salud pública" y justificando con la amenaza de la pandemia, los Poderes Ejecutivos acapararon la tarea legislativa alterando los sistemas constitucionales (Amaya, 2020). Restringiendo una cantidad enorme de derechos fundamentales arbitrariamente en muchos casos, es decir, no respetando las formas establecidas ni fundamentando suficientemente con transparencia sus decisiones.

En el Paraguay, la pandemia de COVID-19 no ha alterado radicalmente el sistema político, sino que más bien, ha demostrado el rostro y la dimensión real del poder político y normativo del Poder Ejecutivo, que dispuso, una serie de medidas restrictivas de derechos fundamentales —sin diálogo, sin debates y sin acuerdos- que decretaron ser necesarias. Y como ocurre normalmente, sin muchas resistencias institucionales. Del anterior razonamiento se deriva que en una situación tan extraordinaria como constituye la de una pandemia global, necesitó tan solo una ley de emergencia, la Ley $\mathrm{N}^{\circ} 6524$ /2020 para cuestiones presupuestarias, administrativas y fiscales, que le otorgaron aún más atribuciones para enfrentarse a la amenaza de la pandemia en el Paraguay.

Normalmente en cuanto al liderazgo político, el presidente administra y ejecuta el presupuesto público y, con ello, controla a miembros de otros poderes y organismos autónomos del Estado. Como es natural en un régimen presidencialista, quien gobierna el Ejecutivo, es el líder político más importante del país. Sumado a esto, por la naturaleza de su poder (ejecutivo) y el proceso para la toma de decisiones, no necesita debatir públicamente ni acordar como sucede en los cuerpos colegiados. Asimismo, tiene a su disposición casi cien ministerios y secretarías dependientes, con cientos de miles de funcionarios públicos, ejecutando más del $90 \%$ del presupuesto público nacional, además de las represas binacionales Itaipú y Yacyretá que tienen presupuestos muy importantes. Igualmente, tiene a su disposición a las Fuerzas Públicas siendo su Comandante en Jefe, entre otras. También, tiene a su favor una visión sociológica del concepto de trabajo en el Paraguay, fruto de años y años de gobiernos autoritarios, según la cual, lo tangible es el trabajo, y el trabajo intelectual -que no se ve- no lo es. Lo anterior, tiene una importancia determinante en la medida del poder público, puesto que la población ve y valora las funciones y las acciones del Poder Ejecutivo como trabajo, en cambio, las funciones deliberativas e intelectuales, características de los otros poderes del Estado no gozan de una valoración positiva asociada con el trabajo. En este sentido, trabaja quien ejecuta obras (construye un puente, una ruta o coloca postes de alumbrado público) pero no trabaja quien se sienta a dialogar, a debatir, a criticar, a razonar y a juzgar (Ayala Miret, 2020).

Por otro lado, si dos países tuvieran exactamente un mismo esquema formal de poder público, contando con historias políticas y condiciones sociales distintas, difícilmente la dimensión y el equilibrio de los poderes en ambos países funcionarían de la misma manera, puesto que el poder no sólo se ejerce conforme a la Constitución formal sino principalmente conforme a la Constitución material. Finalmente, la Constitución intenta poner límites, dar previsibilidad jurídica y un orden al poder público, pero es la sociedad la que finalmente hace respetar esos límites y ese orden jurídico establecido. Así, una conciencia ciudadana acerca de sus derechos, de sus obligaciones, del propósito y del funcionamiento correcto y de los límites del poder público, resulta esencial para que esa 
constitución formal que constituye nuestra norma fundamental y suprema tengan mayor vigencia.

En este sentido, la amenaza de la pandemia del COVID -19 ha sido una demostración clara de ello. Ya que, aunque la Constitución de 1992 no permitía al Poder Ejecutivo decretar restricciones uniformes y generales de derechos fundamentales, con los efectos y los alcances que tuvieron las mismas desde el comienzo de la amenaza de la pandemia, el consenso social y político sobre la necesidad de las mismas, al momento de dictarse estas decisiones, pudo más que la letra de la Constitución y de las leyes.

Al principio, el estado de temor y alarma hizo omitir disposiciones constitucionales sobre las funciones de los poderes y órganos autónomos como: que las leyes de emergencia deben de sancionadas por el Congreso, que el Poder Judicial debe ser independiente, que el Ministerio Público debe velar por el respeto de los derechos y de las garantías constitucionales, entre muchas otras de enorme importancia. En consecuencia, la mayoría de los legisladores observaron al Poder Ejecutivo asumir sus funciones. Mientras que los ministros de la Corte Suprema de Justicia juzgaron la legalidad de las medidas renunciando públicamente a su independencia, la Fiscalía imputó penalmente a miles de ciudadanos y ninguna persona promovió acciones de inconstitucionalidad contra los decretos y resoluciones que restringieron arbitrariamente sus derechos fundamentales.

Pasado un tiempo, luego de algunos escándalos y claros desaciertos del Poder Ejecutivo en el manejo de la emergencia, ya sin tanta paciencia ante la apremiante necesidad económica que causó la cuarentena sanitaria, la sociedad se mostró más crítica. Al principio, el concepto de necesidad fue más grande -incluso cuando en la realidad todavía no existía tal necesidad con pocos casos positivos diarios-, más grande que hoy, ${ }^{4}$ que existen cientos de casos

4. Octubre, 2020. comunitarios positivos de COVID-19 por día y tristemente más de mil personas fallecidas a causa de la enfermedad.

\section{NORMATIVA UTILIZADA Y EXPEDIDA PARA EL ENFRENTAMIENTO DEL COVID-19 EN EL PARAGUAY}

El 23 de enero de 2020, la Dirección General de Vigilancia de la Salud del Ministerio de Salud Pública y Bienestar Social emite la Alerta Epidemiológica $\mathrm{N}^{\circ}$ 1/ 2020 sobre el nuevo coronavirus, recomendando fortalecer las actividades de vigilancia a toda la Red de Vigilancia Epidemiológica, Hospitalaria de primer, segundo y tercer nivel del país, y a todos los miembros de la Red Nacional de Laboratorios de Salud Pública, a fin de detectar cualquier evento inusual de salud respiratoria y notificar de forma inmediata cualquier caso que sea sospechoso para iniciar las acciones de control. Además, esta primera alerta indicó identificar los flujos migratorios y/o nexos de comercio con las zonas afectadas por el virus y realizar un mapeo de comercios frecuentes con China.

Hasta entonces, la Organización Mundial de la Salud (OMS) no recomendaba ninguna restricción de viaje o de comercio, pero alentaba a los países a continuar fortaleciendo su preparación para emergencias sanitarias de conformidad con el Reglamento Sanitario Internacional $(2005)^{5}$. Desde la cartera de Salud del Poder Ejecutivo nacional, a través de esta primera alerta, se indicó recomendar a los viajeros consultar centros asistenciales en caso de presentar síntomas respiratorios agudos, especialmente si provenían de la zona de riesgo (China continental). Considerando el contexto global, habían pasado unos 24 días

\footnotetext{
5. El Reglamento Sanitario Internacional (2005) es un acuerdo de 196 países, incluidos todos los Estados Miembros de la OMS, de trabajar conjunta y coordinadamente en pos de la seguridad sanitaria mundial. El RSI comprende medidas específicas que se deben adoptar en los puertos, aeropuertos y pasos fronterizos terrestres para "prevenir la propagación internacional de enfermedades, proteger contra esa propagación, controlarla y darle una respuesta de salud pública proporcionada y restringida a los riesgos para la salud pública y evitando al mismo tiempo las interferencias innecesarias con el tráfico y el comercio internacionales».
} 
desde la primera alerta a la OMS sobre casos de una "neumonía de causa desconocida» en Wuhan ${ }^{6}, 16$ días desde la primera víctima fatal por un nuevo coronavirus en China, 2 días desde el primer caso detectado en el continente americano, con casos ya detectados en Tailandia, Japón y en Corea del Sur. Ese mismo 23 de enero, China declaró bajo cuarentena toda la ciudad de Wuhan, suspendiendo todo transporte interno como también para el ingreso y la salida de la ciudad. Mientras tanto, la OMS aún no consideraba que este nuevo coronavirus constituya una "Emergencia de Salud Pública de Importancia Internacional" (ESPII).

Unos pocos días después, el 30 de enero de 2020, el Director General de la OMS declaró que el brote del nuevo coronavirus ya constituye una ESPII. Según dicha declaración, en ese momento ya se habían confirmado 7,834 casos mundialmente: unos 7,736 en China (el 99\%) y habían fallecido en ese país unas 170 personas. Fuera de China, había 98 casos confirmados en 18 países sin víctima mortal alguna, incluidos unos 8 casos en cuatro países (Alemania, Japón, EE. UU. y Vietnam) en los que ya se tenían pruebas de transmisión de persona a persona. El Director General, Tedros Adhanom, expresaba que la mayor preocupación de la OMS era que el virus se propague en países con sistemas de salud frágiles y poco preparados para enfrentar la amenaza y resaltaba que la única manera de superarla sería con una colaboración conjunta y solidaria de todos los países.

En el Paraguay, el 25 de febrero de 2020, el Congreso Nacional instó públicamente al Poder Ejecutivo a tomar medidas sanitarias ante el coronavirus "que actualmente se encuentra en expansión a nivel mundial", y a impulsar sistemas de control y mecanismos necesarios para proteger la salud y prevenir la propagación del COVID-19 en el Paraguay. Asimismo, exhortó al establecimiento de planes de contingencia y prevención ante un eventual contagio (Congreso Nacional,

6. Para ver la cronología de la expansión del COVID 19 y de la respuesta de la OMS, véase el vínculo consultado en las referencias del presente artículo.
2020) ${ }^{7}$. En este sentido, el 28 de febrero, el Ministerio de Salud Pública y Bienestar Social (MSPyBS) crea por Resolución S.G. $\mathrm{N}^{\circ} 76$ el Centro Operativo de Emergencia (COE), un equipo técnico responsable de ejecutar y coordinar todas las acciones a implementarse ante una eventual epidemia de COVID-19 en el Paraguay.

El 9 de marzo de 2020, ya con el primer caso confirmado de coronavirus en el Paraguay (ABC Color, 2020), el Poder Ejecutivo publica su primer decreto ${ }^{8}$, el Decreto $\mathrm{N}^{\circ} 3442$ "por el cual se dispone la implementación de acciones preventivas ante el riesgo de expansión del coronavirus (COVID-19) al territorio nacional", instrumento que no disponía acciones concretas sino que se remitía y exhortaba la ejecución del Plan Nacional de Respuesta a Virus Respiratorios 2020, que había sido aprobado por resolución del MSPyBS. Sin embargo, cabe destacar que constituyó el primer instrumento donde se ordena a las Fuerzas Armadas y a la Policía Nacional a colaborar con el MSPyBS.

Un día después, el MSPyBS expide la Resolución $\mathrm{N}^{\circ}$ 90: "Por la cual se establecen medidas para mitigar la propagación del coronavirus" $^{\prime \prime}$ la restricción nada más y nada menos que de derechos fundamentales de manera general por primera vez (SilveroSalgueiro, 2020). Dicha resolución, con la sola firma del Ministro de Salud Dr. Julio Mazzoleni, dispuso de manera uniforme la suspensión por 15 días a nivel nacional de todos los espectáculos públicos o privados de concurrencia masiva, tales como conciertos musicales, encuentros deportivos, reuniones políticas, gremiales y sociales, actividades religiosas y actividades recreativas. Incluso suspendió todo tipo de actividades en lugares

7. Declaración “Que insta al Poder Ejecutivo y demás autoridades, a impulsar sistemas de control y mecanismos necesarios para proteger la salud y prevenir la propagación en nuestro país de le enfermedad coronavirus (COVID-19), que actualmente se encuentra en expansión a nivel mundial".

8. Para ver lista de Decretos (COVID-19) del Poder Ejecutivo refrendados por el Ministro de Salud, véase vínculo disponible en las Referencias.

9. Para ver lista de Resoluciones (COVID-19) del MSPyBS, véase vínculo disponible en las Referencias. 
cerrados, tales como cines, teatros, salas de conferencias, clubes, discotecas, casinos, bares y centros culturales y, por último, todas las actividades educativas en todos los niveles de enseñanza en todo el país. Todo ello bajo la advertencia de que en caso de incumplimiento se aplicarán las sanciones previstas en el Código Sanitario (Ley $\mathrm{N}^{\circ}$ 836/1980). Código sancionado antes que la Constitución de 1992, bajo un esquema distinto de división de poderes del Estado, conforme al cual se dictaban estas drásticas medidas por simple resolución ministerial.

Sin embargo, ello no fue puesto en tela de juicio por los otros Poderes del Estado, salvo por algunos de sus integrantes del Congreso. Cuando el presidente de la república Mario Abdo Benítez — jefe del Poder Ejecutivoanunció públicamente a la población las resoluciones del Ministro de Salud Julio Mazzoleni, se encontraba acompañado en ese acto por todos los presidentes de los otros Poderes del Estado, que sin autorización de sus cuerpos colegiados dieron un respaldo "institucional" de facto otorgando una imagen (ropaje) de legalidad y legitimación ante la población de las medidas claramente inconstitucionales: Blas Llano, presidente del Congreso; Alberto Martínez Simón, presidente de la Corte Suprema de Justicia; y Pedro Alliana, presidente de la Cámara de Diputados $^{10}$.

Por un consenso de los presidentes de los poderes estatales en ese momento acerca de la necesidad de las medidas adoptadas, se estaba configurando al margen del derecho una drástica delegación legislativa en manos de un ministro del Poder Ejecutivo, quien para restringir derechos fundamentales de carácter general y uniforme - con fuerza de ley material- no necesitó someter sus decisiones al proceso democrático correspondiente. No existen dudas de que una decisión de ese carácter y con esos alcances, conforme al orden constitucional paraguayo, sólo lo podía realizar el Congreso. Sin embargo, fue el comienzo de una serie de

10. El vínculo de la noticia y fotografía del anuncio de manera conjunta por las autoridades de los tres poderes del Estado está disponible en las Referencias. restricciones y disposiciones normativas que en la práctica obligaron con fuerza de ley a los habitantes del país.

El 11 de marzo, un día después, la OMS declaraba a la propagación del coronavirus (COVID-19) como una pandemia, ante los niveles alarmantes de expansión, gravedad e inacción. Ante estos hechos globales, y argumentando una falta de acatamiento ciudadano de las medidas preventivas, ${ }^{11}$ el Poder Ejecutivo declara Estado de Emergencia Sanitaria en el Paraguay mediante el Decreto $\mathrm{N}^{\circ} 3456$ y cierra las fronteras nacionales, salvo para el comercio, mediante el Decreto $\mathrm{N}^{\circ} 3458$; ambos el 16 de marzo de 2020. Se destaca el artículo 2 del Decreto $\mathrm{N}^{\circ} 3456$, que autoriza al MSPyBS a disponer un "aislamiento preventivo general por razones sanitarias" desde las 20:00 hasta las 04:00 horas por un plazo a ser determinado por este Ministerio.

Al día siguiente, el 12 de marzo, mediante la Resolución $\mathrm{N}^{\circ}$ 99, el MSPyBS ordena el "aislamiento preventivo general de la población en carácter de cuarentena sanitaria" en todo el territorio paraguayo hasta el día 24 de marzo de 2020, inicialmente. Advirtiendo además que los incumplimientos se sancionarán con las penas establecidas en Ley $\mathrm{N}^{\circ} 836 / 1980$, Código Sanitario, sin perjuicio de las sanciones previstas en la Ley $\mathrm{N}^{\circ} 716 / 95$, que sanciona delitos contra el medio ambiente, y el Código Penal vigente. Materialmente, esta resolución ministerial basada en un decreto presidencial fue incluso más amplia que la declaración de un Estado de Excepción $^{12}$, restringiendo una mayor cantidad de derechos fundamentales y con mayor alcance que lo que se podría afectar con la declaración de un Estado de Excepción previsto en el artículo 288 de la Constitución paraguaya de 1992 . Todo ello,

11. Sin embargo un día después en el Considerando de la Resolución S.G. $N^{\circ} 99$ afirman que las medidas sanitarias han sido acatadas por la mayoría de los habitantes, pero que "existe un sector de la población que no cumple correctamente".

12. Así se denominó al Estado de Sitio en la Constitución de 1992 a fin de asegurar su carácter excepcional, puesto que durante la dictadura se decretaba abusivamente el Estado de Sitio de manera permanente. 
exclusivamente desde el Poder Ejecutivo, sin un proceso o ratificación democrática como exige la Constitución para la declaración del Estado de excepción en el Paraguay.

Conforme a la Constitución paraguaya de 1992, el Congreso es el órgano encargado de regular los derechos fundamentales consagrados en la misma, en todo momento, incluso en los momentos en los que se necesite expedir leyes de emergencia. Esto último, establecido constitucionalmente en el artículo 202, numeral 13, entre los deberes y atribuciones del Congreso. Por otra parte, el Poder Ejecutivo cuenta con la atribución del tratamiento de urgencia, establecida en el artículo 210 de la Constitución, mediante la cual puede solicitar al Congreso el tratamiento urgente de proyectos de ley que envíe al Congreso. Atribución que no ha sido utilizada, ni una sola vez, durante la pandemia por el Poder Ejecutivo. En este sentido, resulta importante destacar que el Poder Legislativo no interrumpió sus actividades legislativas durante la pandemia. El Congreso sesionó activamente desde el inicio de la misma, salvo una breve suspensión de diez días del 3 al 13 de abril, que coincidió con la Semana Santa, por funcionarios que dieron positivo para COVID-19. Luego de esta suspensión, las sesiones legislativas continuaron públicamente de manera virtual.

El día 27 de marzo de 2020, el Poder Legislativo sanciona la Ley $\mathrm{N}^{\circ} 6524$ /2020 declarando estado de emergencia en todo el territorio nacional ante la pandemia declarada por la OMS a causa del COVID-19, estableciendo medidas administrativas, fiscales y financieras. Por medio de esta ley, se autorizó al Poder Ejecutivo a implementar medidas excepcionales de carácter presupuestario, fiscal y administrativo, de protección del empleo y de política económica y financiera, con tres objetivos específicos: 1) fortalecer el sistema de salud, 2) proteger el empleo, y 3) evitar el corte de la cadena de pagos. Todo ello para mitigar o disminuir las consecuencias negativas de la pandemia del COVID-19 y por el presente ejercicio fiscal (2020).
Para el cumplimiento de estos objetivos, el Poder Legislativo no sólo le otorgó una autorización al Poder Ejecutivo para tomar todas las medidas administrativas, fiscales y financieras necesarias, sino también le otorgó autorizaciones presupuestarias para contar con los recursos suficientes para un enfrentamiento efectivo ante una eventual pandemia en el Paraguay. De esta manera, el artículo 3 de la mencionada ley autorizó al Poder Ejecutivo, a través del Ministerio de Hacienda, a modificar el Presupuesto General de la Nación (PGN, 2020) sin pasar por el Congreso, como es exigido ordinariamente. Esto es así ya que las modificaciones del PGN deben ser por ley, sin embargo, con la Ley $\mathrm{N}^{\circ}$ 6524 se autorizó anticipadamente al Poder Ejecutivo a realizar las modificaciones que considere necesarias. Como bien se conoce, el manejo y la ejecución del presupuesto público nacional influye determinantemente en la medida del poder público, que en este caso por amenaza de una pandemia fortaleció aún más al presidente de la república, que también se encargó de determinar los gastos y formular las políticas públicas que ordinariamente corresponden al Congreso de la Nación.

Además de contar con los recursos del Presupuesto General de la Nación de las importantes donaciones nacionales e internacionales, el Poder Ejecutivo contó con la autorización para contratar empréstitos, de manera general, sin necesidad de pasar por el Congreso para la aprobación de cada préstamo y de sus condiciones específicas, hasta el monto de US\$ 1.600 .000 .000 (Dólares americanos un mil seiscientos millones). Esta autorización anticipada del Congreso, simplificando el procedimiento de contratación de empréstitos, y otras autorizaciones extraordinarias para el financiamiento de las medidas de emergencia y los efectos económicos de la crisis sanitaria del COVID-19 están contenidas en el artículo 33 y siguientes de la Ley $\mathrm{N}^{\circ} 6524$.

Para el control de estos súper poderes del Ejecutivo, en la Ley $\mathrm{N}^{\circ} 6524$ se establecieron medidas de transparencia y de rendición de cuentas especiales, en el artículo $41 \mathrm{y}$ siguientes, como la creación de una Comisión 
Bicameral del Congreso para el control de los fondos de emergencia; ${ }^{13}$ la puesta a disposición de las rendiciones de cuentas en internet a través portales de acceso público para la ciudadanía; ${ }^{14}$ y la obligación del Poder Ejecutivo y de los Organismos y Entidades del Estado (OEE) que ejecuten los fondos de emergencia de presentar cada 60 días sus rendiciones de cuentas con un informe al Congreso y a la Contraloría General de la República (CGR), con toda la documentación de respaldo. Respecto a este último punto, cabe destacar que el Poder Ejecutivo incumplió con el deber de informar sobre la ejecución de los fondos dentro de los primeros 60 días establecido en el art. 45 de la Ley de Emergencia (ADN paraguayo, 2020), cumpliendo recién con su obligación ya vencido el plazo. Además, el presidente de la república no aceptó la invitación de la Cámara de Senadores para informar y explicar públicamente a la población ante la misma sobre el uso de los recursos públicos y sobre las acciones que el gobierno central estaba llevando a cabo para la lucha contra el COVID-19. Declinación que fue ampliamente reprochada (Diario Última Hora, 2020), especialmente ante la falta de explicaciones claras y fundamentaciones transparentes sobre las distintas decisiones del gobierno central durante la emergencia, que afectaban a toda la población (ABC Color, 2020).

En contrapartida, el presidente Abdo Benítez decidió invitar solamente a la mesa directiva del Senado a una reunión privada. Respuesta poco feliz, ya que no sólo era de genuino interés público conocer apropiadamente las motivaciones de las numerosas decisiones, decretos y resoluciones -materialmente con fuerza de ley- adoptados por el Poder Ejecutivo, sino que también ya existían numerosas acusaciones (ABC Color, 2020) y denuncias (ABC Color, 2020) de hechos de

13. Comisión integrada por seis senadores y seis diputados, de carácter transitorio y por la duración del presente ejercicio fiscal (2020). Información oficial, documentos e informes de la misma disponibles en el vínculo en las Referencias.

14. Para acceder a dichas plataformas, ingresar a: https://datos.contraloria.gov.py/\#/datos y https:// www.rindiendocuentas.gov.py corrupción (ABC Color, 2020) que afectaban negativamente la gestión y credibilidad en el manejo de la crisis de su gobierno. La ciudadanía que se encontraba haciendo enormes sacrificios para cumplir las medidas del Poder Ejecutivo merecía respuestas. Finalmente, el presidente Mario Abdo envió a sus ministros para rendir cuentas ante el Senado.

Con la ley $\mathrm{N}^{\circ}$ 6524, hemos nombrado ya las tres principales leyes utilizadas por el Gobierno Central para el manejo y el enfrentamiento de la pandemia de COVID-19 en la República del Paraguay. En resumen, el Poder Ejecutivo utilizó y reglamentó de manera profusa, permanente y consecutiva estas tres leyes, a través de resoluciones y decretos, para los siguientes aspectos:

\section{PARA EL ASPECTO SANITARIO}

Fue utilizada la Ley $\mathrm{N}^{\circ} 836 / 1980$ "Código Sanitario". La misma, en su artículo 13, establece que en casos de epidemias el Poder Ejecutivo está facultado a declarar en estado de emergencia la totalidad o parte afectada del territorio nacional, determinando su carácter y estableciendo las medidas procedentes, pudiendo exigir acciones específicas extraordinarias a las instituciones públicas y privadas, así como a la población en general.

Esta ley, como ya mencionamos, es anterior a la Constitución de 1992 y fue sancionada durante la Constitución de 1967 bajo la cual el Poder Ejecutivo tenía mucho mayores atribuciones en comparación con la Constitución de 1992. Esta última, buscó y busca desmantelar el hiperpresidencialismo y el abuso de poder en el Paraguay.

Desde el mes de marzo del 2020, el Poder Ejecutivo ha venido reglamentado continuamente hasta hoy - principios del mes de octubre - esta ley, dictando más de 37 decretos y 32 resoluciones con verdadera fuerza de ley material para la vida de las personas, estableciendo o restringiendo con carácter general y a nivel nacional quiénes y en qué momento pueden trabajar, transitar, ingresar o salir del territorio nacional, deban aislarse en sus casas o en albergues comunes, 
qué empresas pueden abrir, dónde se puede comprar, qué tipo de servicios se consideran básicos o esenciales, entre muchas más. Medidas como las anteriormente señaladas, afectan de manera determinante los derechos constitucionales de las personas.

El Congreso no ha dictado leyes sanitarias de emergencia para esta pandemia. Toda la actividad reglamentaria o legislativa sanitaria de emergencia lo ha realizado el Poder Ejecutivo apoyándose jurídicamente en esta ley del año 1980 y en el artículo 68 de la Constitución de 1992 que paradójicamente establece que: "Toda persona está obligada a someterse a las medidas sanitarias que establezca la ley, dentro del respeto a la dignidad humana".

Recién en el mes de julio de 2020, el Senado aprueba un proyecto de ley que regula aspectos sanitarios estableciendo la obligatoriedad del uso de tapabocas o mascarilla ${ }^{15}$. El mismo, todavía no ha sido sancionado por el Congreso y sigue en trámite en octubre de 2020. En conclusión, todas las normas sanitarias y restricciones a los derechos fundamentales fueron $y$ continúan siendo dictadas a través de Resoluciones y Decretos del Poder Ejecutivo, sin debates públicos ni fundamentaciones claras para regular aspectos tan delicados.

\section{PARA EL ASPECTO PUNITIVO}

Fue utilizada la Ley $\mathrm{N}^{\circ} 716 / 1996$ "Que sanciona delitos contra el medio ambiente", para sancionar a las personas que no cumplan con las medidas sanitarias establecidas en los decretos y resoluciones del Poder Ejecutivo. La misma, en su artículo 10, establece sanciones desde multas $^{16}$ hasta penas privativas de libertad de seis a dieciocho meses a quienes "violen cuarentenas sanitarias". Así tal cual como

15. Proyecto de ley: “QUE DISPONE LA OBLIGATORIEDAD TEMPORAL DEL USO DE MASCARILLAS HIGIÉNICAS O DE ELEMENTOS DE PROTECCIÓN QUE CUBRAN NARIZ, BOCA Y MENTÓN, Y DEL CUMPLIMIENTO DE LAS MEDIDAS DE PROTECCIÓN CONTRA EL COVID 19". Expediente nO. S-209584 (SILPy).

16. Penas pecuniarias desde cien a quinientos jornales mínimos (en moneda local aproximadamente USD 1,200 hasta USD 6,000 al cambio de octubre 2020). se expresa entre comillas, es decir que las causas y las condiciones específicas del hecho punible ${ }^{17}$ fueron establecidas por el Poder Ejecutivo en sus numerosos y cambiantes decretos y resoluciones.

Ello constituye un claro ejemplo de lo que se conoce como leyes penales en blanco, que como bien las define el Prof. Dr. Miguel Abel Souto:

Son preceptos penales principales que contienen la pena, sanción o consecuencia jurídica pero no expresan íntegramente el supuesto de hecho o conducta delictiva, pues el legislador para tales efectos se remite a normas no penales del mismo o inferior rango, a otras leyes, reglamentos o actos de la Administración. (Souto, 2005, p.13)

Este tipo de leyes penales necesitadas de complemento pueden provocar problemas serios y delicados no sólo para los ciudadanos sino también para el sistema constitucional, ya que por medio de ellas se podrían configurar claras violaciones al principio de legalidad, ${ }^{18}$ a la seguridad jurídica y a la división de poderes del Estado (Souto, 2005). Increíblemente, ello no fue objeto de reserva alguna para el Ministerio Público, cuyo deber constitucional establecido expresamente en el artículo 268 es el de velar por el respeto de los derechos y de las garantías constitucionales, sino todo lo contrario, ya que las imputaciones son publicitadas por esta misma institución pública. Solamente al 06 de junio de 2020, el Ministerio Público imputó penalmente a 3295 personas "por hechos punibles relacionados a la Cuarentena Sanitaria, Ley 716/96" (Ministerio Público, 2020). Incluso imputando a ciudadanos que se manifestaron contra la corrupción. (La Unión R800 AM, 2020) y (Ministerio Público, 2020).

Por si ello fuera poco, tampoco la Justicia se mostró objetiva ni independiente ante

17. Que la Constitución paraguaya de 1992 exige en su artículo 11 que sean fijadas por la Constitución y las leyes.

18. Consagrado en el artículo 1 del Código Penal paraguayo vigente, Ley № 1160/97. 
estas medidas penales de dudosa legalidad sino que celebró un convenio con el mismo Ministerio Público para destinar lo que resulte de las penas a los infractores a reparaciones sociales (Figueredo Corrales, 2020). De esta manera, otorgando una aprobación institucional acerca de la legalidad de las penas y fijando gravemente el resultado de las sanciones. Lo anterior resulta especialmente preocupante, puesto que el mensaje que transmite la Corte Suprema de Justicia a los habitantes es el de la legalidad de estas medidas penales, desalentado severamente el ejercicio del derecho fundamental y absoluto de buscar protección y justicia ante el Poder Judicial $\mathrm{y}$, lo más grave, prejuzgando de manera general.

\section{PARA EL ASPECTO ECONÓMICO, PRESUPUESTARIO, FISCAL Y ADMINISTRATIVO}

Fue utilizada la Ley $\mathrm{N}^{\circ} 6524$ /2020, ley especial de emergencia sancionada por el Congreso por medio de la cual se autoriza al Poder Ejecutivo a implementar medidas excepcionales de carácter presupuestario, fiscal y administrativo, de protección del empleo y de política económica y financiera, con tres objetivos específicos: 1) fortalecer el sistema de salud, 2) proteger el empleo, y 3) evitar el corte de la cadena de pagos.

Todo ello con la intención de disminuir las consecuencias negativas de la pandemia del COVID-19 por el presente ejercicio fiscal (2020). La ley que explicamos anteriormente ha tenido una amplia reglamentación por el Poder Ejecutivo, y se le ha realizado modificaciones legales para ampliar aún más su alcance conforme a objetivos específicos. En este sentido, el gobierno central dispuso una serie de medidas económicas estableciendo políticas, atenuaciones y mayor flexibilidad fiscales, así como la prórroga de tributos, la reasignación de gastos públicos, un mayor destino de recursos para la salud pública y la economía, la exoneración del pago de servicios básicos de energía eléctrica y agua, y la creación de subsidios con el nombre de Pytyvõ, Ñangareko, y del Instituto de Previsión
Social (IPS) para empleados suspendidos (Figueredo Corrales, 2020).

\section{¿La Corte defensora de la Constitución y protectora de los derechos fundamentales ante el Poder político?}

Resulta ineludible preguntarse sobre el control de constitucionalidad al "legislador excepcional", es decir, al Poder Ejecutivo, durante la pandemia de COVID-19 por parte de la Corte Suprema de Justicia. De manera insólita, en el Paraguay hasta el momento ${ }^{19}$ no ha existido ningún desafío a la constitucionalidad de las medidas, resoluciones y decretos dictados por el Poder Ejecutivo, en oportunidad de la pandemia de COVID-19, por parte de la Corte Suprema de Justicia. No sólo no ha sido resuelta ninguna acción de inconstitucionalidad, sino que no se ha presentado ninguna ${ }^{20}$. Cabe destacar la utilización y el acompañamiento público de los decretos del Poder Ejecutivo por el presidente y ministros de la Corte Suprema de Justicia, ya que ello pudo tener un efecto paralizador en la población a la hora de buscar protección ante la restricción de sus derechos fundamentales durante la pandemia ante la Corte.

Inoportunamente, la Corte Suprema de Justicia citó expresamente como fundamento jurídico los decretos del Poder Ejecutivo dictados en oportunidad del COVID-19 en sus numerosas Acordadas y demás disposiciones normativas dictadas durante la pandemia (Instituto de Investigaciones Jurídicas CSJ, 2020). ${ }^{21}$ Este mensaje fue claro para toda la ciudadanía paraguaya.

\section{CONCLUSIÓN}

\footnotetext{
19. Mes de octubre de 2020.

20. De acuerdo a las publicaciones oficiales disponibles y entrevistas realizadas a funcionarios de la Corte Suprema de Justicia.

21. El Instituto de Investigaciones Jurídicas de la Corte Suprema de Justicia, reunió todas las Acordadas y disposiciones dictadas por la Corte con relación al COVID- 19 en un libro. Vínculo disponible en las Referencias del presente artículo.

documento disponible en: https://www.pj.gov.py/ ebook/libros_files/acordadas-disposiciones-covid-19iij.pdf
} 
La historia política de la República del Paraguay se caracteriza por largos períodos de autoritarismo por parte de los poderes ejecutivos en el ejercicio del poder público. La Constitución de 1992 sin dudas ha fundado una nueva época de democracia, de derechos, de libertades y de esperanza. Su carácter antiautoritario nos ha asegurado hasta hoy que no volvamos - a pesar de importantes intentos- a períodos oscuros de nuestra historia. Sin embargo, construir una sociedad plenamente democrática es una lucha constante y diaria que no depende solamente del texto de nuestra Ley Suprema. La situación generada por la pandemia de COVID-19, ha sido un llamado serio de atención para permanecer en vigilia y velar por la vigencia plena y permanente de la Constitución, aún más en periodos de emergencia.

La construcción de una ciudadanía democrática, consciente y comprometida será cada vez más necesaria para los tiempos presentes y futuros. Resulta indispensable cuidar la vigencia continua de un verdadero equilibrio -formal y material- de los poderes del Estado, de manera que los mismos funcionen correcta y coordinadamente para la misión que fueron creados: la de proteger y de garantizar la libertad, la democracia constitucional y nuestros derechos fundamentales.

\section{REFERENCIAS BIBLIOGRÁFICAS}

» Abdo emite decreto para aplicar plan contra propagación de coronavirus (09 de marzo de 2020). ABC Color. Recuperado el 06 de octubre de 2020 de: https:// n9.cl/9fvzr

» Amaya, J. A. (2020) Control de constitucionalidad y consulta legislativa ¿Hacia un sistema mixto de control federal? Revista Jurídica La Ley Paraguaya, 43 (6), 1685-1715.

" Areces, N. R. (2010). De la Independencia a la Guerra de la Triple Alianza (1811-1870). En I. Telesca (Ed.), Historia del Paraguay (pp. 149-197). Asunción, Paraguay: Taurus-Santillana.

» Ayala Miret, R. (2018). Constitución, Poder y Límites: Una breve reflexión sobre la prohibición absoluta de la reelección presidencial en el Paraguay ante una posible Reforma Constitucional. Revista Jurídica CEDUC - UCA Law Review, (27), 287-294.

» Ayala Miret, R. (Julio de 2020). La complejidad del Estado contemporáneo y su impacto en el equilibrio de los poderes del Estado. Derecho Procesal y Constitucional comparado durante el Covid-19. Seminario Internacional (online) llevado a cabo en Buenos Aires, Argentina.

» Comisión Bicameral del Congreso (2020). Control de los Recursos Previstos en la Ley de Emergencia № 6524/2020. Recuperado 4 de octubre de 2020 de: https:// n9.cl/q0bra.

» Congreso Nacional de Paraguay (2020). Congreso insta al Ejecutivo tomar medidas sanitarias ante el coronavirus. Recuperado 25 de septiembrede 2020 de: https://n9.cl/yroau.

» Contraloría concluye que la adjudicación estuvo totalmente viciada (21 de mayo de 2020) Diario ABC Color. Recuperado 6 de agosto de 2020 de: https:// n9.cl/n13o3

» Coronavirus: Gobierno Suspende las clases y toda aglomeración de perso- 
nas. (10 de marzo de 2020). Diario ABC Color. Recuperado 6 de junio de 2020 de https://n9.cl/hixj.

» Críticas por declinación de Mario Abdo ante invitación del Senado (02 de junio de 2020). Diario Última Hora. Recuperado 04 de agosto de 2020 de: https://n9.cl/ lmum.

» Dirección General de Vigilancia de la Salud del Ministerio de Salud Pública y Bienestar Social. (2020) Alerta Epidemiológica $N^{\circ} 1 / 2020$. Recuperado de http:// www.vigisalud.gov.py/files/alertas/SE4_2020_Alertas.pdf

» Ejecutivo incumple ley de emergencia que lo obliga a rendir cuentas sobre uso de los recursos cada 60 días (27 de mayo de 2020). ADN Paraguayo. Recuperado 08 de septiembre de 2020 de: https://n9.cl/rt6lr.

» Figueredo Corrales, R. F. (2020). La pandemia de la COVID-19: Constitución, Estado y salud. Revista Jurídica Paraguaya La Ley, 43 (7), 2035-2036.

» Filártiga Callizo, C. (2016) La estabilidad del sistema de partidos de Paraguay (1989-2015) Los sistemas de partidos en América Latina 1978-2015. Flavia Freidenberg, ed. Universidad Nacional Autónoma de México (UNAM) Ciudad de México.

» Grassi: "No podemos estar imputado por algo que no existe en el código penal paraguayo". (30 de septiembre de 2020). La Unión R800 AM. Recuperado 3 de octubre de 2020 de: https://n9.cl/69wnt.

» Instituto de Investigaciones Jurídicas (2020). Covid-19 Acordadas y Disposiciones dictadas por la Corte Suprema de Justicia. Recuperado de https://n9.cl/ayws.

» Licitación amañada ya estaba adjudicada y firmada por Mazzoleni, afirman. (24 de mayo de 2020). Diario ABC Color. Recuperado 25 de junio de 2020 de: https:// n9.cl/tvk8.

》 Los senadores invitan a Abdo para que explique los negociados (29 de mayo de 2020). Diario ABC Color. Recuperado 2 de agosto de 2020 de: https://n9.cl/srpn4.

» Mateo Balmelli, C. (1995). El Desarrollo Institucional. Asunción, Paraguay: Editorial El Lector.

» Ministerio de Salud Pública y Bienestar Social (2020). Decretos COVID-19. Recuperado de https://www.mspbs.gov.py/decretos-covid19.html

» Ministerio de Salud Pública y Bienestar Social (2020). Plan Nacional de Respuesta a Virus Respiratorios 2020. Recuperado 02 de junio de 2020 de: https:// n9.cl/5v5qc.

» Ministerio de Salud Pública y Bienestar Social (2020). Resoluciones COVID-19. Recuperado 15 de septiembre de 2020 de: https://www.mspbs.gov.py/resoluciones-covid19.html

» Ministerio Público (2020). Coronavirus: Fiscalía imputó a 3.295 personas en todo el país por violación a la cuarentena sanitaria. Recuperado 30 de septiembre de 2020 de: https://www.ministeriopublico.gov.py/nota/coronavirus-fiscaliaimputo-a-3295-personas-en-todo-el-pais-por-violacion-a-la-cuarentena-sanitaria-5270

» Ministerio Público (2020). Fiscal imputó a abogada por violación de la cuarentena sanitaria. Recuperado 30 de junio de 2020 de: https://n9.cl/a6ww6.

Negretto, G. L. (2015). La política del cambio constitucional en América Latina. 
Ciudad de México, México: Fondo de Cultura Económica.

» Nickson, A. (2010). El Régimen de Stroessner (1954-1989). En I. Telesca (Ed.), Historia del Paraguay (pp. 265-294). Asunción, Paraguay: Taurus-Santillana.

» Organización Mundial de la Salud (2005). Reglamento Sanitario Internacional. Tercera edición. Recuperado de https://www.who.int/ihr/publications/9789241580496/es/

» Organización Mundial de la Salud (2020). Cronología de la respuesta de la OMS a la COVID-19. Recuperado de https://www.who.int/es/news/item/2906-2020-covidtimeline

» Organización Mundial de la Salud (2020). Declaración del Director General de la OMS sobre la reunión del Comité de Emergencia del Reglamento Sanitario Internacional acerca del nuevo coronavirus (2019-nCoV). Recuperado 02 de octubre de 2020 de: https://n9.cl/fang1.

» Riquelme, M. (1994). Towards a Weberian characterization of the Stroessner regime in Paraguay (1954-1989). European Review of Latin American and Caribbean Studies, (57), 29-51.

» Silvero-Salgueiro, J. (2020). El impacto del COVID-19 en el sistema político paraguayo: ¿hacia una democracia iliberal?. En L. G. Arcaro Conci (Ed.) O Direito Público en tempos pandêmicos: 9 países, 11 trabalhos e una porção de inquietudes (pp. 137149). São Paulo, Brasil: Tirant lo Blanch.

» Souto, M. A. (2005). Las leyes penales en blanco. Nuevo Foro Penal, (68), 13-30.

» Una "oportunidad" para que Abdo Benítez explique cada decisión tomada durante la pandemia (29 de mayo de 2020). Diario ABC Color. Recuperado 19 de junio de 2020 de https://n9.cl/dnq7e 